\title{
COMPARATIVE PHYTOCHEMICAL AND ANTIOXIDATIVE CHARACTERIZATION OF TRIFOLIUM PRATENSE L. AND OCIMUM BASILICUM L.
}

\author{
INA-ANDREEA ANTONESCU (MINTAS) ${ }^{1}$, TUNDE JURCA ${ }^{2}$, FELICIA GLIGOR ${ }^{3}$, IZABELA \\ CRACIUN $^{3}$, LUMINITA FRITEA $^{1}$, EVA BRIGITTA PATAY $^{4}$, MARIANA MURESAN $^{1}$, \\ DENISA IOANA UDEANU ${ }^{5}$, CORINA ANA IONIȚA ${ }^{5}$, ANGELA ANTONESCU ${ }^{1 *}$, FLORIAN $^{2}$ \\ BODOG $^{6}$
}

\author{
${ }^{I}$ University of Oradea, Faculty of Medicine and Pharmacy, Department of Preclinical Disciplines, Oradea, Romania \\ ${ }^{2}$ University of Oradea, Faculty of Medicine and Pharmacy, Department of Pharmacy, Oradea, Romania \\ ${ }^{3}$ University' 'Lucian Blaga', Sibiu, Faculty of Medicine and Pharmacy, Department of Pharmacy, Sibiu, Romania \\ ${ }^{4}$ University of Pecs, Faculty of Pharmacy, Department of Pharmacognosy, Pecs, Hungary \\ ${ }^{5}$ University of Medicine and Pharmacy "Carol Davila", Faculty of Pharmacy, Department of Clinical Laboratory and Food \\ Safety, Bucharest, Romania \\ ${ }^{6}$ University of Oradea, Faculty of Medicine and Pharmacy, Department of Surgery, Oradea, Romania
}

*corresponding author: antonescu.angela@yahoo.com

\begin{abstract}
The phytochemical composition of Trifolium pratense L. and Ocimum basilicum L. was investigated by using chromatographic and spectrophotometric methods. T. pratense extract was rich in ferulic acid $(237.48 \mathrm{mg} / 100 \mathrm{~g}$ dry weight) and chlorogenic acid $(158.50 \mathrm{mg} / 100 \mathrm{~g}$ dry weight), meanwhile $O$. basilicum extract presented the highest concentration in ferulic acid $(437.58 \mathrm{mg} / 100 \mathrm{~g}$ dry weight). The determination of total phenolic and flavonoid contents indicated that $O$. basilicum contained the highest amounts $(67.89 \mathrm{mg} \mathrm{GAE} / 100 \mathrm{~g}$ dry extract and $6.49 \mathrm{mg}$ QE/mL extract respectively), aspect which was corelated with its strongest antioxidant activity assessed by DPPH (2,2-diphenyl-1-picrylhydrazyl), FRAP (ferric reducing antioxidant power) and CUPRAC (cupric reducing antioxidant capacity) methods.
\end{abstract}

\section{Rezumat}

Compoziția fitochimică a speciilor Trifolium pratense L. și Ocimum basilicum L. a fost investigată folosind HPLC și o metodă spectrofotometrică. Extractul de T. pratense a fost bogat în acid ferulic $(237,48 \mathrm{mg} / 100 \mathrm{~g}$ extract uscat) şi acid clorogenic $(158,50$ $\mathrm{mg} / 100 \mathrm{~g}$ extract uscat), în timp ce extractul de O. basilicum a prezentat cea mai mare concentrație de acid ferulic $(437,58$ $\mathrm{mg} / 100 \mathrm{~g}$ extract uscat). Determinarea conținutului total de compuşi fenolici și flavonoide a arătat că $O$. basilicum a conținut cele mai mari cantități $(67,89 \mathrm{mg} \mathrm{GAE} / 100 \mathrm{~g}$ extract uscat și respectiv $6,49 \mathrm{mg} \mathrm{QE} / \mathrm{mL}$ extract), aspect corelat cu activitatea sa antioxidantă cea mai puternică, evaluată prin metodele DPPH (2,2,-difenil-1-picrilhidrazil), FRAP (puterea antioxidantă reducătoare a fierului) şi CUPRAC (capacitatea antioxidantă reducătoare a cuprului).

Keywords: Trifolium pratense, Ocimum basilicum, total phenolic content, total flavonoid content, antioxidant activity

\section{Introduction}

Basil (Ocimum basilicum L.) is an ornamental, medicinal and aromatic herb from Lamiaceae family being native in Asia, Africa and India, but it is widely cultivated in many countries in the world. Its fresh and dried leaves are used as a spice in food industry. Basil also has a wide range of applications in cosmetic and pharmaceutical industries due to the essential oils from leaves and flowers which can be used as aroma additives in foods, cosmetics and pharmaceuticals $[35,16]$. Being a popular plant, it was also used in traditional medicine in the treatment of headaches, coughs, diarrhoea, constipation, warts, worms and kidney malfunction. Moreover, there are information in scientific literature about its antioxidant, antibacterial, antidiarrheal [21], antifungal [11], cardioprotective and plasma lipid lowering activity (in the treatment of hyperlipidemia and atherosclerosis) [1]. In addition, the major aroma compounds (1,8-cineole, methyl eugenol, linalool, methyl chavicol etc.) from the volatile extracts of basil present antibacterial and antioxidant activity [9, 10, 12, 25].

Red clover (Trifolium pratense L.) is a short-lived biennial plant from Fabaceae or Leguminosae family which is native in Mediterranean area (Turkey), but it is also widespread throughout the entire United States [6]. Trifolium is the most important and numerous taxa from this family concerning the agricultural and medicinal use [17]. 
In traditional medicine it was used for the treatment of asthma, whooping cough, eczema and eye diseases and as chemoprotective agent against cancers and cardiovascular diseases. Moreover, some herbalists collect it for its antispasmodic, expectorant, alterative and sedative effect [6]. In addition, the anti-inflammatory [38], antioxidant, anticestodal, cytostatic, cytotoxic, and antibacterial effect were intensively studied [8]. Nowadays, this plant is popular especially for its estrogenic activity used for the treatment of menopausal symptoms [17]. The most important compounds identified in leaves being responsible for this activity are the estrogenic isoflavones (biochanin A, formononetin, daidzein, genistein) $[6,18]$. Due to its potential use in menopause as a natural form in hormone replacement therapy, a lot of nutritional supplements obtained from $T$. pratense L. are available [6, 8].

Free radicals are different metabolic products of human body which are unstable and highly reactive. Due to the ability to be electron donor or acceptor, they can behave as oxidants or reductants. The most dangerous oxygen-containing free radicals are hydroxyl, superoxide anion, hydrogen peroxide, oxygen singlet, hypochlorite, nitric oxide, and peroxynitrite which can arise from tobacco smoke pollutants, radiation, organic solvents, pesticides [35]. Moreover, the appearance of these free radicals in human body can cause oxidative damage of biomolecules which can increase the occurrence of cardiovascular and inflammatory diseases, cancer and diabetes. Nowadays people are focused on antioxidants naturally found in many plants, foods and beverages because they are able to protect against cellular damage caused by free radicals in the body $[13,14,37,24]$. In addition, they have less secondary effects as synthetic antioxidants [28].

Phenolic compounds are one of the most widespread groups of phytochemicals in plants which show considerable physiological, morphological and biological importance. Since polyphenols are able to scavenge free radicals, to donate hydrogen atoms or electron or to chelate metal cations, they possess significant antioxidant activity useful for both plants and human body [41, 29].

Chlorogenic and ferulic acids are biologically active substances, more precisely polyphenols which present numerous physiological effects for human body. From the chemical point of view, chlorogenic acids are a group of esters formed between quinic acid and trans-hydroxycinnamic acids (e.g. caffeic, ferulic and $p$-coumaric acid), and sometimes from dimethoxycinnamic, trimethoxycinnamic and sinapic acids. They show a significant antioxidant, anti-inflammatory, antibacterial and anti-influenza effect [19, 20]. Ferulic acid (4hydroxy-3-methoxycinnamic acid) is a trans- hydroxycinnamic acid and its anti-hyperglycaemic, antioxidant and anti-inflammatory properties as well as the protection activity against Alzheimer's disease were also studied [32, 34].

Moreover, it is supposed that their role in plants is a protecting one against pathogens and abiotic stress (modifications of temperature, water content, exposure to UV light levels and deficiency in mineral nutrients) [28]. Chlorogenic and ferulic acids can exist in both cis- and trans- isomers in plants and the exposure to UV radiation can determine their geometric isomerization [7, 28, 32]. The presence of the antioxidants such as chlorogenic, p-hydroxybenzoic, caffeic, vanillic, rosmarinic acids, apigenin, quercetin and rutin was successfully studied in basil [35].

Even though the red clover is popular owing to the estrogenic effect, the antioxidant effect was also proven and the identified flavonoids, phenolic acids, clovamides and saponins are responsible for this radical scavenging activity $[8,35]$.

For the investigation of the antioxidant capacity, a wide range of methods based on the quantification of the free radical scavenging capacity have been developed. DPPH (2,2-diphenyl-1-picrylhydrazyl) method is a spectrophotometric assay widely used to test the ability of compounds to remove free radicals or their ability to release hydrogen. It is used to quantify antioxidants in complex biological systems [31]. FRAP method (ferric reducing antioxidant power) is a simple spectrophotometric method based on the reduction process of ferric tripyridyltriazine (Fe(III)-TPTZ) complex to ferro tripyridyltriazine (Fe(II)-TPTZ) complex in acidic pH [31]. CUPRAC method (cupric reducing antioxidant capacity) is based on changes in the absorption characteristics of the complex $\mathrm{Cu}$ (II)neocuproine during the reduction by an antioxidant $[2,3,31]$.

Despite the available and valuable scientific information about the $O$. basilicum and $T$. pratense, there are no comparative studies related to their antioxidant activity and phytochemical composition. Therefore, the aim of this study was to realise a comparative work of the two plants concerning their chemical composition and antioxidant activity by using various techniques such as: HPLC, DPPH, FRAP, CUPRAC and Folin-Ciocalteu.

\section{Materials and Methods}

\section{Materials}

\section{Plant materials and samples preparation}

The plant materials used in this study consisted in the herba of red clover and basil and were purchased from S.C. ADSERV S.R.L and S.C. STEF MAR S.R.L. The hydro-alcoholic extracts were obtained by mixing the plant materials with a 
FARMACIA, 2019, Vol. 67, 1

hydro-alcoholic mixture $70 \%(1: 10 \mathrm{w} / \mathrm{v})$ under stirring 20 minutes and ultrasonication for 5 minutes. The resulted extracts dried in vacuum by using a rotary evaporator. Each dry extract was transferred to a flask with $10 \mathrm{~mL}$ of distilled water and then lyophilized at $-25^{\circ} \mathrm{C}$.

Chemicals and reagents

All chemical reagents were of analytical grade. Absolute ethanol was purchased from Merck, sodium carbonate and gallic acid from Fluka. The other reagents such as: 6-hydroxy-2,5,7,8-tetramethylchromane-2-carboxylic acid (Trolox), potassium persulfate, Folin-Ciocalteu reagent, 2,2-diphenyl-1pycrylhydrazyl (DPPH), 2,4,6-Tri(2-pyridyl)-striazine (FRAP) were purchased from Sigma Aldrich.

Chromatographic conditions and HPLC analysis

The polyphenols determination from the two vegetal extracts was performed by using an Agilent 1200 HPLC system equipped with a diode array detector (PDA). A Zorbax SB-C18 column (250 x $4.6 \mathrm{~mm}, 100 \mathrm{~A}, \mathrm{~S} / \mathrm{No}$ 86996-11, B/No: 5701-029) was used. The mobile phase was a binary gradient consisting in the mobile phase A (distilled water formic acid (99.9:0.1) (v/v)) and mobile phase B (acetonitrile). Other employed acquisition parameters were as follows: flow rate $1.5 \mathrm{~mL} / \mathrm{min}$, injection volume $10 \mu \mathrm{L}$, column temperature $25^{\circ} \mathrm{C}$ and detection wavelengths: $230,260,290,300$ and 360 $\mathrm{nm}$ [27].

The identification of polyphenols from red clover and basil extracts was performed by comparing the retention times obtained for the extract with those of the standard solutions. The standard solutions were prepared by mixing $1 \mathrm{~mL}$ stock standard solutions of gallic acid, cinnamic acid, caffeic acid, ferulic acid, siringic acid, catechin, rutin (flavonoid) (1000ppm) and $1 \mathrm{~mL}$ of chlorogenic acid stock standard solution (500ppm) and injected in triplicate. The stock standard solutions and the extracts were prepared using $30 \%$ ethanol as solvent. A preliminary spectral scanning was performed for each stock standard solution obtaining the maximum absorbance as follows: gallic acid, catechin, siringic acid at $230 \mathrm{~nm}$, rutin at $260 \mathrm{~nm}$, cinnamic acid at $290 \mathrm{~nm}$ and clorogenic, ferulic, caffeic acids at $300 \mathrm{~nm}$ [22].

The determination of total phenolic content

The total polyphenolic compounds content was spectrophotometrically assessed by using FolinCiocalteu method. The absorbance at $765 \mathrm{~nm}$ wavelength linearly increases with the number of hydroxyl groups from anthocyanins. The blue compounds formed between phenolates and the Folin-Ciocalteu reagent are independent of the structure of phenolic compounds, thus generating complexes between the metallic center and the phenolic compounds. The spectrophotometric analyses were recorded on Shimadzu mini UV-Vis by using an absorption wavelength of $765 \mathrm{~nm}$. The total polyphenol concentration in the extracts was calculated from the regression equation being expressed in $\mathrm{mg}$ gallic acid equivalent (GAE)/100 $\mathrm{g}$ of dry sample. $[15,23,30,33]$.

The determination of total flavonoid content

The total flavonoid content was determined by using a colorimetric method previously reported [38]. The method is briefly described, as it follows: $1 \mathrm{~mL}$ sample (containing $0.1 \mathrm{mg} / \mathrm{mL}$ of dried substance) was mixed with water, $5 \% \mathrm{NaNO}_{2}, 10 \%$ $\mathrm{AlCl}_{3}$ and $1 \mathrm{M} \mathrm{NaOH}$. The absorbance was measured at $510 \mathrm{~nm}$ wavelength using the spectrophotometer Shimadzu mini UV-Vis. The total flavonoid content was expressed as $\mathrm{mg}$ quercetin equivalent $(\mathrm{QE}) / \mathrm{mL}[15,23]$.

The determination of antioxidant activity

DPPH (2,2-diphenyl-1-picrylhydrazyl) method

The inhibition percentage of DPPH (1,1-diphenyl2-picrylhydrazyl) was calculated according to the absorbance recorded at $515 \mathrm{~nm}$ for the control and sample inhibitions $[15,23,40]$.

FRAP method (ferric reducing antioxidant power)

The FRAP working solution was freshly prepared by mixing $50 \mathrm{~mL}$ of $300 \mathrm{mM}$ acetate buffer with $\mathrm{Fe}_{2}\left(\mathrm{SO}_{4}\right)_{3}$ solution and TPTZ. The samples $(100 \mu \mathrm{L}$ each) reacted with FRAP solution and the absorbance was read at $595 \mathrm{~nm}$. Trolox was used as standard and for the calibration curve. The results were expressed in $\mu$ mol Trolox equivalents (TE)/100 g sample [15, 23].

CUPRAC method (cupric reducing antioxidant capacity)

The reduction potential of the sample or of the standard reduces $\mathrm{Cu}^{2+}$ to $\mathrm{Cu}^{+}$changing the maximum absorbance. This reduced copper complex presents a maximum absorption at 450 $\mathrm{nm}$. The calibration curve was obtained using a known concentration of Trolox and the data have been expressed as $\mu \mathrm{mol}$ Trolox equivalents [4].

\section{Results and Discussion}

\section{HPLC analysis}

The qualitative and quantitative determination of the polyphenols from the two vegetal extracts was performed by using the external standard method. The following seven standard polyphenols have been analysed and determined in the composition of $T$. pratense and $O$. basilicum extracts by HLPC method: catechin, syringic acid, cinnamic acid, chlorogenic acid, caffeic acid, ferulic acid and rutin. The chromatograms obtained for the two extracts indicated some differences concerning their chemical compositions (Table I and Table II).

In the case of $T$. pratense extract, ferulic acid and chlorogenic acid were found in the highest concentrations, namely $237.48 \mathrm{mg} / 100 \mathrm{~g}$ and 
FARMACIA, 2019, Vol. 67, 1

$158.50 \mathrm{mg} / 100 \mathrm{~g}$, respectively. The other polyphenols, cinnamic acid, caffeic acid, syringic acid, catechin and rutin were detected in lower concentrations than the two compounds mentioned above (Table I).

Table I

The polyphenols found in $T$. pratense extract

Compound
Cinnamic acid
Caffeic acid
Ferulic acid
Siringic acid
Catechin
Rutin

$\begin{gathered}\text { Area } \\ (\mathbf{m A U})\end{gathered}$
227.89067
189.79274
3692.78442
385.05032
230.85509
532.60583

Chlorogenic acid $\quad 553.2476$

Retention
time (min.)
16.615
11.615
13.533
11.614
9.967
12.456
9.610

Wavelength

290

Assay

(mg/100 g DW)

40.62

$300 \quad 237.48$

$230 \quad 42.43$

$230 \quad 36.63$

$260 \quad 86.21$

DW - dry weight

$300 \quad 158.50$

The results are according to previous studies regarding the polyphenol content of $T$. pratense, which sustain the presence of chlorogenic and ferulic acid but the concentration of the last one was lower than level detected in this study [26, 36]. Meanwhile, in some other studies, similar active principles had been identified except for rutin, which was not detected in $T$. pratense extracts by HPLC method [36].

$O$. basilicum extract is very rich in ferulic acid presenting a concentration of $437.58 \mathrm{mg} / 100 \mathrm{~g}$ extract. This concentration of ferulic acid is almost double than the one found in the $T$. pratense extract, but the other polyphenols concentration was lower in comparison with the $T$. pratense (Table II).

Table II

The polyphenols found in $O$. basilicum extract

Compound
Cinnamic acid
Caffeic acid
Ferulic acid
Siringic acid
Catechin
Rutin

DW - dry weight

$\begin{gathered}\text { Area } \\ (\mathbf{m A u})\end{gathered}$
121.26615
135.87656
6804.39600
109.02885
78.81796
309.99445
31.15704

31.15704
Previous studies regarding the composition of $O$. basilicum collected from Romania geographical area and using DPPH and ABTS methods, determined a lower antioxidant effect of the methanolic extracts and a decreased concentration of caffeic acid than in our samples [10]. Differences in the polyphenol levels were also reported in some studies which determined higher concentrations of the caffeic acid and rutin, but lower levels of the chlorogenic and ferulic acids than in our extracts [5].

Total phenolic and flavonoid analysis

The highest antioxidant activity is usually detected in methanolic and ethanolic plant extracts [35]. Thus, we used 70\% hydro-alcoholic extracts for total phenolic and flavonoid determinations.

In case of the basil extract, the ethanol concentration of $70-80 \%$ was most suitable for the extraction of polyphenols than $50 \%$ ethanol, maybe

$\begin{array}{ccc}\begin{array}{c}\text { Retention } \\ \text { time (min.) }\end{array} & \begin{array}{c}\text { Wavelength } \\ \text { (nm) }\end{array} & \begin{array}{c}\text { Assay } \\ \text { (mg/100g DW) }\end{array} \\ 16.491 & 290 & 5.26 \\ 11.559 & 290 & 29.09 \\ 13.544 & 300 & 437.58 \\ 11.553 & 230 & 12.01 \\ 10.071 & 230 & 12.49 \\ 12.486 & 260 & 50.18 \\ 9.714 & 300 \mathrm{~d} & 8.94\end{array}$

because many natural polyphenols are soluble in ethanol and less soluble in water. The optimal influence of ethanol on the extraction process was previously reported, indicating that high polyphenols level could be achieved by using an increased concentration of ethanol (70-80\% aqueous solution of ethanol) [5].

The phenolic and flavonoid compounds are very important taking into consideration their significant antioxidant properties. The comparative data concerning the contents of total phenols and flavonoids from the two extracts are presented in Table III. The highest amount of phenols was determined for $O$. basilicum (67.89 mg GAE/100 g dry extract). The same aspect was observed in case of the total flavonoid content, its quantity being almost double in $O$. basilicum extract $(6.49 \mathrm{mg}$ $\mathrm{QE} / \mathrm{mL}$ ) in comparison with red clover ( $T$. pratense) sample (Table III). 
Table III

The total phenolic and flavonoid contents found in T. pratense and O. basilicum extracts

\section{Samples}

Trifolium pratense

Ocimum basilicum content (mg GAE/100g DW)

46.56

67.89
Total flavonoid

content (mg QE/mL)

3.44

6.49
Because methanol is a more effective solvent than ethanol, some studies reported similar total phenolic content, but a higher total flavonoid content of $T$. pratense in comparation with our study [8].

Other authors, by using different solvents, reported a higher level of the total flavonoid in T.pratense than in our samples but the total phenolic content was lower than those obtained from our ethanolic extracts [17]. Moreover, in the same study, the antioxidant effect and total polyphenol and flavonoid contents determined in $O$. basilicum extracts were not in concordance with our results reporting a lower concentration of the total phenolic content, a higher concentration of the total flavonoid content than in our extracts, a decreased antioxidant capacity studied by DPPH method [16]. All these differences can be explained by the use of different extraction methods [16]. The total phenolic and flavonoid concentration reported in this study were higher than the

\section{Antioxidant activity} DPPH \%

FRAP mg TE/mL CUPRAC mmol Trolox/100 g

By using the DPPH assay, O. basilicum extract demonstrated the greatest radical scavenging activity $(35.62 \%)$, being more than double in comparison with $T$. pratense $(14.49 \%)$. These results are in good agreement with the phenolic and flavonoid contents listed in Table III. In spite of the similarities found in the total phenolic and flavonoid contents reported by other studies, the antioxidant activity of $O$. basilisum extracts was more significant in our samples as detected by DPPH method [5, 35].

Previous studies reported an increased antioxidant activity of the $T$. pratense extracts in comparison with our samples which were in correlation with concentration reported by another study regarding the Romanian species of O. basilicum [5].

The high concentration of polyphenols found in $O$. basilicum is mainly responsible for its therapeutic use considering the anti-inflammatory, antimicrobial or diuretic properties [5].

The presence of active compounds depends on a wide range of factors such as: plant species, genetic factors, geographical location, differences in growth, the soil type, time and season for harvesting, methods for the herb processing etc. [5]. Therefore, the determination of a well-defined and constant composition of the product are one of the most important preliminary requirements for producing an efficient therapeutic product.

Antioxidant activity tests (DPPH, FRAP and CUPRAC) The antioxidant capacity of both extracts was assessed by several methods and the results are presented in Table IV.

Table IV

Antioxidant activity of red clover and basil extracts

$\begin{array}{cc}\text { Trifolium pratense } & \text { Ocimum basilicum } \\ 14.49 & 35.62 \\ 17.14 & 17.32 \\ 2.72 & 3.22\end{array}$

their data regarding total phenolic and flavonoid content [8]. Several other studies reported significant antioxidant capacity of T.pratense by using different solvents or other methods of detection than DPPH or FRAP $[17,36]$.

The CUPRAC technique also indicated a higher antioxidant potential of $O$. basilicum extract, meanwhile the results obtained by using the FRAP method were similar for both samples.

Moreover, a positive correlation was found between the antioxidant capacity and the total phenolic and flavonoid content of the studied $O$. basilicum and $T$. pratense extracts. The results are presented in Figure 1. 


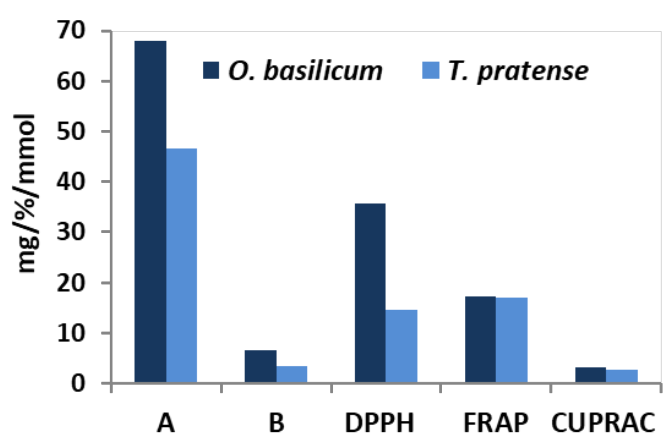

Figure 1.

The positive correlation between the antioxidant activity (DPPH\%, FRAP mg TE/mL, CUPRAC mmol Trolox $/ 100 \mathrm{~g}$ ) and total phenolic and flavonoid content of the studied plant samples: A-total phenolic content (mg GAE/100g dry extract); B-total flavonoid content (mg QE/mL)

\section{Conclusions}

A phytochemical study was carried out on the extracts of two vegetal products, $T$. pratense and $O$. basilicum. HPLC-UV method was performed for the identification and quantification of the polyphenols. $O$. basilicum extract was the richest in ferulic acid, meanwhile $T$. pratense extract presented higher concentrations of other active principles, especially for chlorogenic acid. The highest total phenolic and flavonoid contents were determined in case of the $O$. basilicum samples highlighting its strongest antioxidant activity measured by DPPH, FRAP and CUPRAC methods. These results indicate that these two species could be valuable natural sources of antioxidants with therapeutic perspectives.

\section{Acknowledgement}

The study was supported by the project "The interrelation between leptin, oxidative stress markers and pro-inflammatory cytokines in patients with chronic renal failure", number 62/01.12.2010.

\section{Conflict of interest}

The authors declare that there is no conflict of interest.

\section{References}

1. Adegbola P, Aderibigbe I, Hammed W, Omotayo $\mathrm{T}$, Antioxidant and anti-inflammatory medicinal plants have potential role in the treatment of cardiovascular disease: a review. Am J Cardiovasc Dis., 2017; 7(2): 19-32.

2. Apak R, Guclu K, Ozyurek M, Celik SE, Mechanism of antioxidant capacity assays and the CUPRAC (cupric ion reducing antioxidant capacity) assay. Microchim Acta, 2008; 160: 413419.

3. Apak R, Guculu K, Ozyurek M, Karamedir SE, Novel total antioxidant capacity index for dietary polyphenols and vitamins $\mathrm{C}$ and $\mathrm{E}$, using their cupric ion reducing capability in the presence of neocuproine: CUPRAC method. J Agric Food Chem., 2004; 52: 7970-7981.

4. Arnao MB, Some methodological problems in the determination of antioxidant activity using chromogen radicals: a practical case. Trends Food Sci Technol., 2000; 11: 419-421.

5. Benedec D, Vlase L, Hanganu D, Oniga I, Antioxidant potential and poliphenolic content of Romanian Ocimum basilicum. Digest Journal of Nanomaterials and Biostructures, 2012; 7: 12631270.

6. Booth NL, Overk CR, Yao P, Totura S, Deng Y, Hedayat AS, Bolton JL, Pauli GF, Farnsworth NR, Seasonal variation of red clover (Trifolium pratense L., Fabaceae) isoflavones and estrogenic activity. $J$ Agric Food Chem., 2006; 54(4): 1277-1282.

7. Clifford MN, Kirkpatrick J, Kuhnert N, Roozendaal $\mathrm{H}$, Rodrigues Salgado P, LC-MSn analysis of the cis isomers of chlorogenic acids. Food Chemistry, 2008; 106: 379-385.

8. Esmaeili AK, Taha RM, Mohajer S, Banisalam B, Antioxidant activity and total phenolic and flavonoid content of various solvent extracts from in vivo and in vitro grown Trifolium pratense L. (red clover). BioMed Research International, 2015; 2015: 1-11.

9. Filip S, Vidovic S, Vladi J, Pavli B, Adamovic D, Zekovi Z, Chemical composition and antioxidant properties of Ocimum basilicum L. extracts obtained by supercritical carbon dioxide extraction: Drug exhausting method. The Journal of Supercritical Fluids, 2016; 109: 20-25.

10. Gird CE, Costea T, Nencu I, Dutu LE, Popescu L, Balaci TD, Comparative pharmacognostic analysis of romanian Ocimum Basilicum L. and $O$. Basilicum Var. Purpurascens Benth. aerial parts. Farmacia, 2015; 63(6): 840-844.

11. Helmy Abou El-Soud N, Deabes M, Abou ElKassem L, Khalil M, Chemical composition and antifungal activity of Ocimum basilicum L. essential oil. Open Access Macedonian Journal of Medical Sciences, 2015; 3(3): 374-379.

12. Joshi RK, Chemical composition and antimicrobial activity of the essential oil of Ocimum basilicum L. (sweet basil) from Western Ghats of North West 
Karnataka, India. Anc Sci Life., 2014; 33(3): 151156.

13. Jurca T, Vicas L, Marian E, Vicas S, Muresan M, A new natural antioxidant supplement - design and development. Farmacia, 2016; 64(1): 135-142.

14. Jurca T, Marian E, Vicaș L, Gâtea D, Simultaneous determination of metals in Hypericum perforatum L. by ICP-OES. Revista de Chimie, 2011; 62(12): 1154-1156.

15. Jurca T, Vicas L, Toth I, Braun M, Marian E, Teusdea A, Vicas S, Muresan M, Mineral elements profile, bioactive compounds and antioxidant capacity of wild blueberry and of pharmaceutical preparation from Bluberry (Vaccinum myrtillus). Farmacia, 2016; 64(4): 581-587.

16. Kaurinovic B, Popovic M, Vlaisavljevic S, Trivic $\mathrm{S}$, Antioxidant capacity of Ocimum basilicum L. and Origanum vulgare L. extracts. Molecules, 2011; 16: 7401-7414.

17. Kaurinovic B, Popovic M, Vlaisavljevic S, Schwartsova H, Vojinovic-Miloradov M, Antioxidant profile of Trifolium pratense L. Molecules, 2012; 17: 11156-11172.

18. Klejdus B, Vitamvásová-Štěrbová D, Kubán̆ V, Identification of isoflavone conjugates in red clover (Trifolium pratense) by liquid chromatographymass spectrometry after two-dimensional solidphase extraction. Analytica Chimica Acta, 2001; 450(1-2): 81-97.

19. Liang N, Kitts DD, Role of chlorogenic acids in controlling oxidative and inflammatory stress conditions. Nutrients, 2016; 16: 1-20.

20. Liu Z, Zhao J, Li W, Shen L, Huang S, Tang J, Duan J, Fang F, Huang Y, Chang H, Chen Z, Zhang R, Computational screen and experimental validation of anti-influenza effects of quercetin and chlorogenic acid from traditional Chinese medicine. Scientific Reports, 2016; 6: 1-9.

21. Lua Y, Gaoa B, Chenc P, Charles D, Yua L, Characterization of organic and conventional sweet basil leaves using chromatographic and flowinjection mass spectrometric (FIMS) fingerprints combined with principal component analysis. Food Chem., 2014; 154: 262-268.

22. Marian E, Vicaș LG, Jurca T, Mureasan M, Stan RL, Sevastre B, Diaconeasa Z, Ionescu C, Hangan AC, A comparative study on the biologic activity of Centaurea cyanus versus Calendula officinalis. Farmacia, 2017; 65(6): 940-946.

23. Marian E, Vicas LG, Jurca T, Muresan M, Pallag A, Stan RL, Sevastre B, Diaconeasa Z, Ionescu CML, Hangan AC, Salvia officinalis L. and Verbascum phlomoides L. chemical, antimicrobial, antioxidant and antitumor investigations. Revista de Chimie, 2018; 69(2): 365-370.

24. Mocan A, Vodnar DC, Vlase L, Crișan O, Gheldiu AM, Crișan G, Phytochemical characterization of Veronica officinalis L., $V$. teucrium L. and $V$. orchidea Crantz from Romania and their antioxidant and antimicrobial properties. International Journal of Molecular Sciences, 2015; 16: 21109-21127.

25. Muráriková A, Tažk A, Neugebauerová J, Planková A, Jampílek J, Mucaji P, Mikuš P, Characterization of essential oil composition in different basil species and pot cultures by a GC-MS Method. Molecules, 2017; 22(7): 1-13.

26. Olah NK, Hanganu D, Vlase L, Cobzac C, The study of polyphenols from Trifolium pratense L. and Medicago sativa L. hydroalcoholic extracts by HPLC-UV-MS. Studia Universitatis Babeș-Bolyai Chemia, 2010; 55(2): 353-362.

27. Pallag A, Bungău SG, Ţiţ DM, Jurca T, Sîrbu V, Honiges A, Horhogea C, Comparative study of polyphenols, flavonoids, and chlorophylls in Equisetum Arvense T. populations. Revista de Chimie, 2016; 67(3): 530-533.

28. Patay EB, Sali N, Kőszegi T, Csepregi R, Balázs VL, Németh TS, Németh T, Papp N, Antioxidant potential, tannin and polyphenol contents of seed and pericarp of three Coffea species. Asian Pacific Journal of Tropical Medicine, 2016; 9(4): 366-371.

29. Pirvu L, Nicorescu V, Hlevca C, Udeanu DI, Nicorescu I, Antimicrobial and synergistic activity of some whole and selective Epilobium hirsutum L. (great willowherb) extracts tested on standard and wild Staphylococcus aureus strains. Farmacia, 2015; 63(5): 690-695.

30. Pirvu L, Sha'at F, Miclea LC, Savopol T, Neagu G, Udeanu DI, Moisescu MG, Polygonum bistorta L. herba et flores polyphenols profile, antioxidant properties and cytotoxic effect on murine fibroblast cell line NIH3T3. Farmacia, 2017; 65(4): 571-576

31. Pisoschi AM, Pop A, Cimpeanu C, Predoi G, Antioxidant capacity determination in plants and plant-derived products: A review. Oxidative Medicine and Cellular Longevity, 2016; 2016: 1- 36.

32. Sgarbossa A, Giacomazza D, di Carlo M, Ferulic ACID: A Hope for Alzheimer's disease therapy from plants. Nutrients, 2015; 7: 5764-5782.

33. Singleton VL, Orthofer R, Lamuela Raventos RM, Analysis of total phenols and other oxidation substrates and antioxidants by means FolinCiocalteu reagent. Methods Enzymol., 1974; 299: 152-178.

34. Sompong W, Cheng $\mathrm{H}$, Adisakwattana S, Protective effects of ferulic acid on high glucoseinduced protein glycation, lipid peroxidation, and membrane ion pump activity in human erythrocytes. PloS One, 2015; 10(6): 1-12.

35. Teofilović Nevena Grujić-Letić B, Goločorbin Kon $\mathrm{S}$, Stojanovic $\mathrm{S}$, Vastag $\mathrm{G}$, Gadžurić $\mathrm{S}$, Experimental and chemometric study of antioxidant capacity of basil (Ocimum basilicum) extracts. Industrial Crops and Products, 2017; 100: 176182.

36. Tundis R, Marrelli M, Conforti F, Tenuta MC, Bonesi M, Menichini F, Loizzo MR, Trifolium pratense and $T$. repens (Leguminosae): Edible flower extracts as functional ingredients. Foods, 2015; 4: 338-348.

37. Velescu BS, Anuta V, Nitulescu GM, Olaru OT, Ortan A, Ionescu D, Ghica MV, Dragoi CM, Dinu Pirvu CE, Pharmaceutical assessment of Romanian crops of Anthriscus sylvestris (Apiaceae). Farmacia, 2017; 65(6): 824-831.

38. Widyarini S, Spinks N, Husband AJ, Reeve VE, Isoflavonoid compounds from red clover (Trifolium 
pratense) protect from inflammation and immune suppression induced by UV Radiation. Photochemistry and Photobiology, 2001; 74(3): 465-470.

39. Zhishen J, Mengcheng T, Jianming W, The determination of flavonoid contents in mulberry and their scavenging effects on superoxide radicals. Food Chemistry, 1999; 64(4): 555-559.

40. Zhu K, Zhou H, Qian H, Antioxidant and free radical -scavenging activities of wheat germ protein hydrolysates (WGPH) prepared with alkalase. Process Biochemistry, 2006; 41(6): 12961302.

41. Złotek U, Mikulska S, Nagajek M, Wieca M, The effect of different solvents and number of extraction steps on the polyphenol content and antioxidant capacity of basil leaves (Ocimum Basilicum L.) extracts. Saudi Journal of Biological Sciences, 2016; 23: 628-633. 